\title{
One by One - Insights into Complex Immune Responses through Functional Single-cell Analysis
}

\author{
Klaus Eyer
}

\begin{abstract}
Immune responses are highly dynamic and complex. The successful completion thereof involves and needs many different cells from the immune system, and requires their specific interactions and functions. Individual cells are the functional units within any immune response, and their varying frequencies and degrees of activity shape and define the response. The state, activation and ultimately functionality of immune cells displays high dynamic heterogeneity. Hence, there is a need for quantitative high-throughput systems that allow for a dynamic and functional single-cell phenotyping, linking function to the individual cells. In this regard, my research group focuses on developing and applying technologies and analytical strategies that allow us to measure, describe and exploit functionality within the immune system, resolved down to the individual, primary cell, to study novel and unique research questions. While doing ex vivo measurements, we are aiming to understand the functionalities of the extracted cells in vivo, within the context of our applied disturbance - vaccination, infection or malignant transformation.
\end{abstract}

Keywords: Antibody repertoire · Deep-functional phenotyping · Droplet microfluidics · Immunization · Single-cell analysis

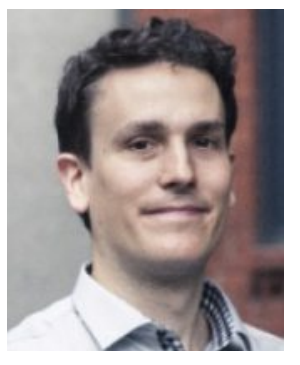

A citizen of Naters, Switzerland, Klaus Eyer finished his studies in Pharmaceutical Sciences at ETHZurich in 2010 with the federal diploma and ETH medal. In 2014, he received his medaled doctoral degree from the laboratory of Prof. Dittrich at the Institute of Organic Chemistry at ETH Zurich. He left Switzerland thereafter and started as a Postdoctoral fellow in the groups of Prof. Bibette and Prof. Griffiths at the ESPCI in Paris. In 2016, he was awarded a Branco-Weiss-Fellowship, and continued as a junior group leader at ESPCI and associated researcher at Institute Pasteur in Paris. He received an ERCstarting-grant in 2018, and started his current position as a nontenure track assistant professor at the Institute of Pharmaceutical Sciences, ETH, in August 2019. His group focuses on developing novel analytical strategies to understand the functionalities of individual cells in the context of complex cellular systems, such as the immune system and its reactions in health and disease. The research of his group currently focuses on gathering knowledge to advance the understanding of vaccine-mediated protection and finding novel diagnostic, prognostic, and therapeutic strategies in various immune-related diseases and syndromes.

\section{Introduction - Functionality within the Immune System}

Ultimately, the goal of any induced immune response is to limit the damage to the organism and to overcome the threat. These threats can be of various natures. Viruses, bacteria, fungi, or malignant transformations are all influencing homeostasis; and are potentially damaging for the organism. These hazards vary tremendously in their nature and in their interactions with healthy tissues, and the immune system needs to counter each threat with a specific, functionally tailored response. While the clearing of infections with the influenza virus has been linked to the presence of neutralizing antibodies, ${ }^{[1]}$ the immunological functions needed to overcome a bacterial infection are different. Most extracellular bacteria are efficiently eliminated by complement deposition, phagocytosis or the combination thereof. ${ }^{[2]}$ Various additional effector functions are further at the disposal of the immune system, ranging from the induction of specific antibodies, the formation of insoluble immune complexes to the destruction of target cells through various antibody-mediated or cellular mechanisms, ${ }^{[3]}$ to only name a few (Fig. 1A).

\subsection{Antibodies as Functional Mediators}

Upon encountering a specific threat, the immune response needs to generate specialized functionally appropriate effector cells. Antibody-secreting cells and their secreted products are often prominent mediators in this process. ${ }^{[4]}$ The cells themselves, as well as their products, display high heterogeneity, and the processes to generate a functionally protective antibody repertoire are highly complex and dynamic. ${ }^{[5]}$ Indeed, an infection is able to induce a very complex and heterogeneous antibody repertoire that shows high variance in terms of biochemical composition ( $>10^{3}$ different antibodies in serum) and biophysical descriptors (affinity, specificity) ${ }^{[6]}$ that is secreted by different populations of cells. Interestingly, every generated antibody-secreting cell contributes only one antibody variant to this complex mixture, ${ }^{[7]}$ and the cellular secretion rate, the number of secreting cells (both corresponding ultimately to concentration) and the affinity for the target will define whether the antibody is able to interact with the target in a meaningful manner. However, as discussed before, binding by itself can also be just the starting point for a variety of other, secondary effects of antibodies. Additional differences in antibody isotype (immunoglobulin $(\operatorname{Ig}) \mathrm{G}, \operatorname{IgM}, \operatorname{IgA}$ and others) 
A

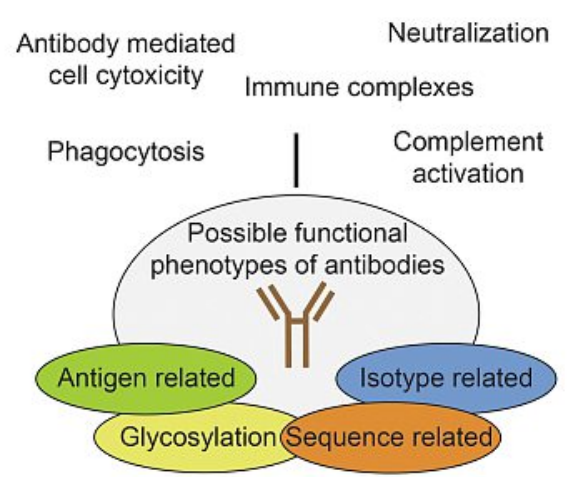

B

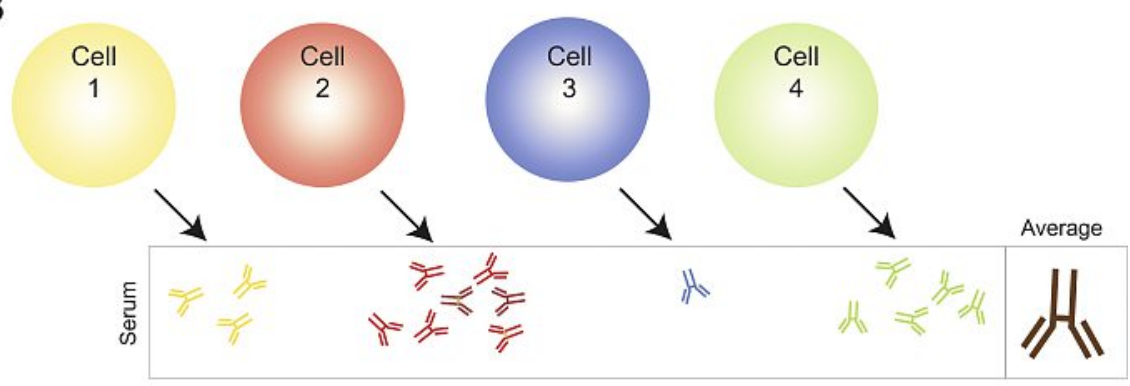

Fig. 1. A) Various secondary functions can be triggered by antibodies within the immune system. The potential of an antibody to do so is related to the paratope sequence and antibody isotype, glycosilation, as well as depending on the nature of the antigen that is recognized. Only a selection of potential secondary functions is depicted in the figure. B) Since each antibody-secreting cell only secretes one type of antibody at a given time, the compartmentalization enables to analyze the antibody repertoire with single-antibody resolution as compared to the current standard titer measurement that averages over thousands of antibodies.

and subtypes (IgG1, IgG2a, etc.) further complicate the picture; and define the ways in which the antibody is able to interact with the other cells from the immune system. ${ }^{[2,3]}$ Only a subset of antibodies are functionally relevant and help the immune system to overcome the threat.

\subsection{Heterogeneity and the Need for Single-cell Analysis}

All these parameters show that the antibody-producing cells and their products are highly variable, a variability that is masked by measuring their average within the serum (Fig. 1B). Similar heterogeneities, but of different nature, are found in other effector cell-populations, such as T cells that display high variability in the amounts and combinations of cytokines produced. ${ }^{[8]}$ Cells from the immune system, their state, activation and ultimately functionality display high dynamic heterogeneity, and there is hence a need for quantitative high-throughput systems that allow dynamic, functional single-cell phenotyping, linking function to the individual cells. My research group focuses on developing technologies and novel analytical strategies that allow us to apply these in novel scientific questions to measure, describe and exploit functionality within the immune system. We do so with single-cell resolution, and link various functionalities to these individual cells. While performing our measurements ex vivo, we aim to understand the functionalities of the extracted cells in vivo, and within the context of our applied disturbance or intervention - vaccination, infection, or malignant transformation. Therefore, our work not only includes the measurement of these functions on the individual cell level, but also involves the development of protocols for gentle and quick cell purification, and the development, integration and characterization of novel bioassays that allow us to quantify functionalities of interest. After thorough validation, we then apply our developed assays and systems to a variety of fundamental and applied scientific questions, and the next paragraphs give glimpses in our past and current research efforts to decipher, understand and exploit active immune responses using functional single-cell analysis.

\section{Measuring Individual Cells Using the DropMap Technology}

During my postdoctoral time at the ESPCI in Paris, I led the development and characterization of a technology that now allows my laboratory and collaborators to measure and quantify the functionalities of individual immune cells, called DropMap (Fig. 2). ${ }^{[9]}$ During its development, I laid focus on developing a simple, flexible but robust system that allows the measurement of many different functionalities in the shortest time frame possible.
The DropMap workflow begins with the compartmentalization of individual cells in monodisperse $50 \mathrm{pL}$ aqueous droplets by using droplet microfluidics, ${ }^{[9]}$ with inert fluorinated carrier oil physically isolating the content of each droplet (droplet volume corresponds to a diameter of $42 \mu \mathrm{m}$, for comparison the cell diameter of a standard mammalian cell is $10-15 \mu \mathrm{m}$, Fig. 2A). The dilution of any molecule produced by the cell is limited and controlled due to the monodisperse droplet size, and the small volume of $50 \mathrm{pL}$ leads to measurable, nanomolar concentrations of most produced molecules in a few seconds to minutes. The droplet production chip contains three inlets to introduce the outer phase (fluorinated carrier oil containing fluorosurfactant), the suspension of cells, and the assay reagents, respectively. The chip further displays an outlet for collecting the produced droplets. Due to the geometry of the chip design, cells and assay reagents are only brought together once they are encapsulated $(<10 \mathrm{~ms})$, minimizing cellular interactions and influences in front of singularization. The microfluidic designs, as well as the chips for droplet production, are fabricated in-house by using standard processes such as soft lithography in poly(dimethylsiloxane) (PDMS). ${ }^{[10]}$

After generation of the droplets, they are directly transferred into the observation chamber, the heart of the DropMap technology. In its core, the observation chamber consists of two transparent surfaces at the top and bottom, and the height of the chamber is slightly smaller than the droplet diameter $(-15 \%) .{ }^{[9]}$ Hence, the inserted droplets rearrange in a stable two-dimensional array (Fig. 2A). This stable immobilization of the droplets allows for time-course measurements of droplet-based biological assays using standard fluorescence microscopes and to study functionality dynamically over time. The formed layer remains stable over hours to days, far longer than the few minutes needed to achieve functional measurements. Incubations and observations over time are made possible for short to medium time ranges (5 min to $<24 \mathrm{~h}$ ) at temperatures between $4{ }^{\circ} \mathrm{C}$ and $37{ }^{\circ} \mathrm{C}$, depending on the scientific question at hand. The observation chamber can be re-used over months, and various sizes of incubation chambers can be built, adapted on the availability of cells, and the fraction of functionally active cells within the sample. One square centimeter allows the continuous observation of around 60 '000 droplets (i.e. 12'-24'000 individual cells) with 2-5 min intervals and a standard size built on a $1 \times 3$ inch glass slide allows the kinetic functional study of up to $225^{\prime} 000$ droplets (i.e. 45'000-90'000 individual cells). The number of cells per droplet follows Poisson distribution, and the number of cells per droplet is adjusted to prevent multiple cells to be present, resulting in a majority of empty droplets. However, various sizes are at disposal to be made in-house, allowing to vary the throughput between 200 and 1'000'000 cells. 
A

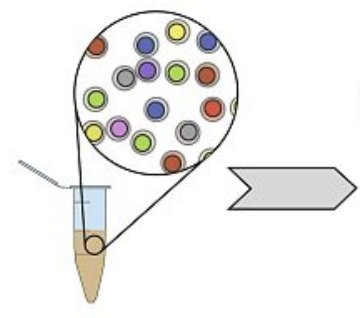

Cell suspension

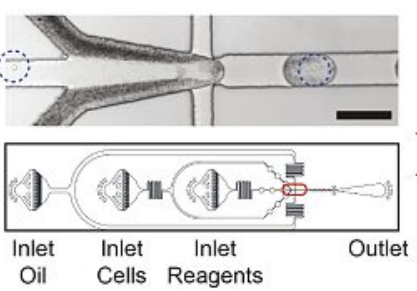

Encapsulation and isolation

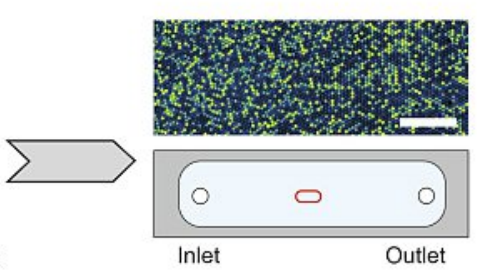

Dynamic analysis of function

B
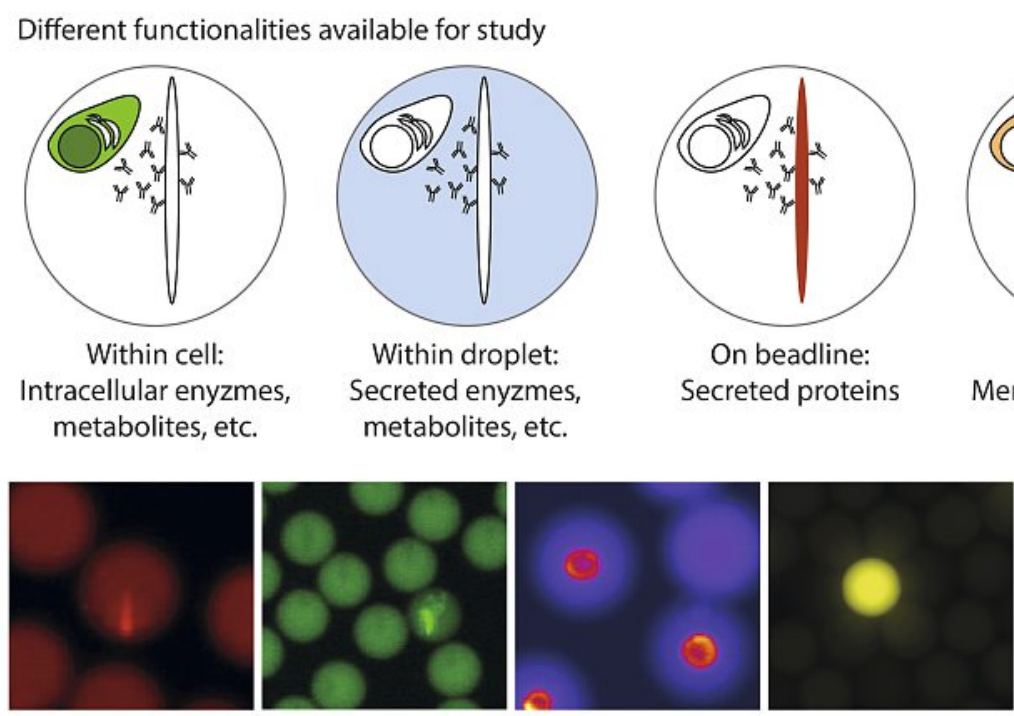

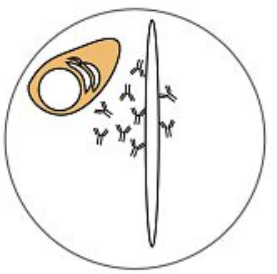

On cell:

On beadline:

Secreted proteins

Membrane receptors, proteins, etc.

Fig. 2. A) Overview of the DropMap workflow. Cells are extracted from the tissue of interest and prepared as a single-cell suspension. The individual cells are then compartmentalized in droplets using microfluidic droplet technology. The top insert shows the nozzle area where the droplets are generated at a frequency of $1-2 \mathrm{kHz}$, and the blue circles indicate individual cells that are encapsulated. The bottom shows a scheme of the used microfluidic device, with the nozzle area indicated in red. Afterwards, the droplets are mapped in the observation chamber where cellular functionality is measured over time. Scale bars are $50 \mu \mathrm{m}$ and $1 \mathrm{~mm}$. B) The DropMap technology is based on measuring changes in fluorescence. Functionality can be assessed within the cell, within the droplet, on the beadline and on the cell surface. Several assays can also be combined, and the correlative measurement of 5-8 functions is possible. The bottom row shows example images of various assays, from left to right: Antibody secretion, CK19 shedding, CD123 expression, lactate secretion and antibody-mediated phagocytosis.

\subsection{Cell Purification and Encapsulation}

In our experiments, we are interested in quantifying and characterizing the in vivo functions of individual immune cells, and cell purification and the quantification of induced stresses and alterations are an important aspect of our work. The protocol for cell encapsulation has been optimized over the last years to be as 'stress-free' as possible, and needs constant adaption to the used cells. However, the quick encapsulation (5-10 min) allows speeding up the process - all favorable for conserving in vivo induced functionality. Due to subsequent measurements of functionality, the impact of introduced alterations in the protocols can be easily quantified. We have established standard operating procedures for many different tissues and functionalities of interest, and cell lines, mononuclear peripheral monocytes as well as cells from the spleen, lymphatic tissues or bone marrow from multiple species have so far been successfully encapsulated and introduced into the system, and their functionalities assessed. Due to the encapsulation within small volumes, at some point nutrient depletion and $\mathrm{pH}$ changes will become a limiting factor for long-term studies of the encapsulated cells. ${ }^{[9]}$ However, we have not only confirmed the survival of primary cells over a $12 \mathrm{~h}$ time span but were also not able to find differences to bulk measurements from cells incubated in optimized conditions. On the contrary, cell lines continue to duplicate over at least $12 \mathrm{~h}$ in the array; and bacteria even grow for several weeks (unpublished observations).

\subsection{Measuring Functionality - Developing Bioassays}

Our main research focus lies in the ex vivo analysis of in vivo immune functions. Functions in the immune system are often mediated by both cell-membrane receptors and secretion of soluble factors, notably antibodies, chemokines and cytokines, and are accompanied by changes in cellular activity and states. Therefore, an integral part of our work is to develop assays that enable us to quantify functionality in a manner that is compatible with high- throughput screenings and consequently allow the characterization of the heterogeneity of immune cells. Development is followed by thorough characterization and validation of these novel bioassays that are often leaning towards simplified versions of physiologically relevant processes. The goal of this assay development is to remove complexity without sacrificing relevance and information.

Since many functionalities in the immune system are controlled by secreted and soluble factors, such as cytokines, chemokines, cytotoxic enzymes or antibodies, my group focused first on the development of methods to quantify these secreted factors (Fig. 2B). To quantify secreted proteins, we developed an in-droplet sandwich immunoassay based on paramagnetic nanoparticles. ${ }^{[9]}$ To perform these assays, the paramagnetic nanoparticles are precoated with a capture reagent against the target of interest - usually an antibody that binds either a specific cytokine, chemokine or other antibodies. Within each droplet, a few hundred to thousands of these nanoparticles are encapsulated (depending on the expected secretion rates), and by applying a magnetic field the particles are induced to form an elongated, observable aggregate, we termed beadline. The use of nanoparticles increases the capacity of the employed assays and adds additional flexibility to determine the measurement range. If the cell now produces the analyte of interest, the secreted protein will bind to the beadline, and relocate a fluorescently labeled detection antibody that is also present in the droplet (Fig. 3). The resulting fluorescence relocation can be readout as an increase in fluorescence on the beadline, normalized by the background fluorescence in the droplet, and can be calibrated using known protein standards to relate the measured signal to the concentration of the analyte. Since we can follow the increase in the concentration of the analyte in each droplet over time, the secretion rate becomes accessible for each cell individually. In addition, the frequency of secreting cells can be extracted by automatic counting of droplets with relocation above a certain threshold, and are measured as a fraction of all present cells. 

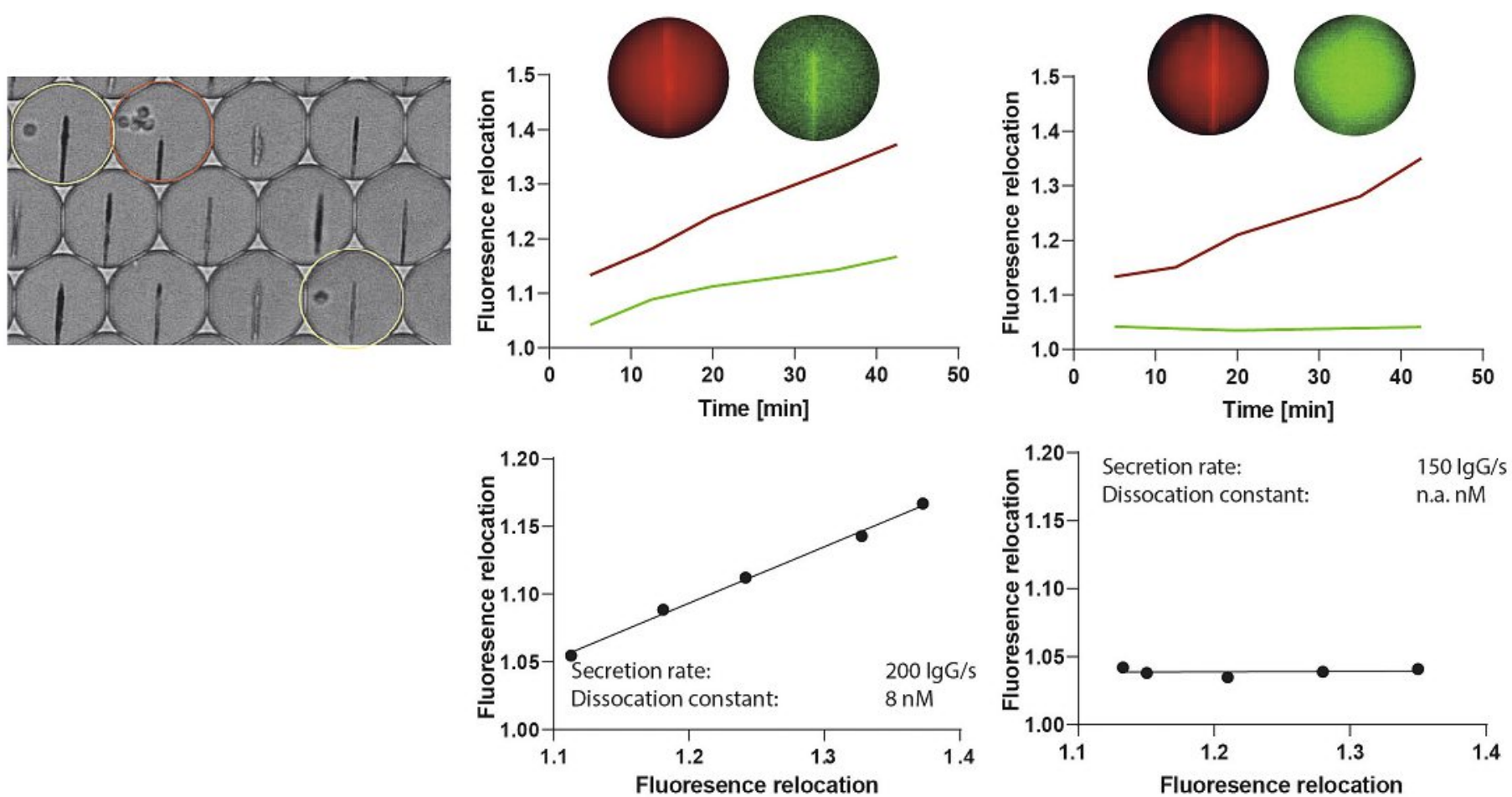

Fig. 3. The left side of the figure shows a micrograph of individual murine antibody-secreting cells in $50 \mathrm{pL}$ droplets. The analysis software detects droplets containing individual cells (yellow), and excludes droplets with no (not shown) or multiple cells (red). The empty droplets are analyzed separately, and are used as an internal negative control. Here, we deployed an assay to measure antibody secretion and affinity against an antigen of interest in parallel. The smaller micrographs show the fluorescence relocation for a cell secreting lgG that bind to the target antigen (center), and the fluorescence relocation to the beadline for a cell of similar secretion rate with no affinity (right). By measuring both fluorescence relocation values in relation to each other (bottom), affinity and secretion rates are accessible. See also Eyer et al. for more information. ${ }^{[9]}$

This assay has been used to quantify the secretion or shedding of up to 20-40 different markers, ranging from different antibody isotypes, and a variety of murine and human cytokines (including TNF- $\alpha$, IFN- $\gamma$; IL-2 and IL-6), to shed membrane proteins (Fig. 2B). All of these secreted molecules are quantified using a fluorescence relocation-based, sandwich immunoassay as described above. To identify cells and characterize membrane bound effector molecules, a similar relocation assay can be designed, measuring relocation (and therefore protein concentration) on the cell membrane. Alternatively, the droplet volume can also be used for biochemical reactions, such as for the measurement of secreted, small metabolites where no antibody pairs can be found - such as lactate, ATP or other. Several fluorescence channels can be used to measure different analytes, and up to 5-6 different functionalities can be measured in parallel, allowing to correlate various functionalities to the individual cell (Fig. 2B). We are currently working on strategies to increase this number to enable even more complex correlative studies of functionality.

\subsection{Vaccination, Protection and Antibody Heterogeneity}

Vaccines have a tremendously positive effect on individual and global health. Vaccines prevent individuals and groups of individuals from disease due to an immediate and preparatory immunological response. Although vaccination has been used for centuries, the understanding of immunological reactions upon vaccination is still limited. Nowadays, successful vaccination is tested by measuring the antibody level within the serum. ${ }^{[11]}$ Although simple to perform, this measure does not necessarily correlate with protection and the relationship between the two can be complicated. Additionally, this measure does not allow to resolve potential differences in the underlying mechanisms that generate, evolve and store functional repertoires that ultimately mediate protection. Therefore, vaccine development and testing is mostly based on empirical evidence, which hinders and deceler- ates the development of new vaccines.[12] Within my laboratory, we aim to measure, understand and describe antibody-mediated protection that is induced by vaccination, following the proposal as it is outlined in the ERC-STG-2018 'FuncMab'. By doing so, we aim to not only measure and describe the functional antibody repertoires, but also to understand the influences of varying vaccine composition, quality, quantity, and application routes on the antibody repertoire. The overarching objective of this project is to quantitatively map antibody functions on the single-cell level, and to use these data sets to understand the selection mechanisms involved in their generation, evolution and transfer to memory; and finally to exploit the measurement to screen for therapeutic candidates and to accelerate vaccine development.

To measure the secretion of antibodies, we used the fluorescence relocation assay described in the previous subchapter, with paramagnetic nanoparticles coated with an anti-antibody immobilization and detection reagent. This allowed us to extract the frequency of secreting cells, as well as their individual secretion rates and the distribution thereof in our experiments. However, due to the described heterogeneity in functionality (Fig. 1A), affinity, isotype and specificity are of further interest. We added fluorescently labeled antigen and other secondary isotype-specific antibodies in different fluorescence channels to the droplets. If the secreted $\mathrm{IgG}$ recognizes the antigen of interest, fluorescence relocation is observed in the antibody detection channel as well as in the antigen channel (Fig. 3). In addition, the relocation in the antibody channel can be calibrated to extract the concentration of antibody, and the assay enables us to calculate the strength of the interaction of the antibody with the antigen with the antibody, the dissociation constant $K_{\mathrm{d}}$. This was thoroughly characterized by multiple model antibodies, antigens and antibody-secreting cell lines. ${ }^{[9]}$ The murine IgG assay is able to quantitatively extract the $K_{\mathrm{d}}$ over a dynamic range of $4 \operatorname{logs}(0.1-500 \mathrm{nM}$ for murine IgG2), covering the typical range of affinities found in antibodymediated responses. While all curves differ in the extent of reloca- 
tion, the general trend and shape are highly conserved. In addition to the frequency of secreting cells and their secretion rates, the assay allowed a deep-phenotypic biophysical characterization of the secreted antibody repertoire, allowing to extract affinity (fluorescence relocation of target antigen) and specificity of each antibody (fluorescence relocation of irrelevant/closely related antigens) using an affinity threshold of $K_{\mathrm{d}}<500 \mathrm{nM}$. This threshold is further used to calculate the frequency of antigen-affine antibody-secreting cells that can be displayed as the frequency of total analyzed cells. All in all, we aim to use these in-depth quantitative parameters to describe the immune response, and to decipher the influence of different vaccination protocols (Fig. 4). Due to ethical concerns and restrictions to work in humans, we mostly work in murine model systems in these projects, but also expand to other species, including healthy human donors if the research questions allow to justify, and expanding these experiments to a human setting.

In our first study, we followed the generation, evolution and transfer of the $\mathrm{IgG}$ repertoire by using a snapshot analysis at more than 15 different days in various immunologically relevant compartments, achieving a good temporal and spatial resolution of the induced immune reaction. ${ }^{[9]}$ The goal was to describe and study the kinetics and dynamics behind affinity maturation that ensue vaccination in their full detail. Using DropMap, we characterized the antibody-secreting cells in mice immunized with tetanus toxoid as a model antigen over a 7-week immunization protocol, simultaneously analyzing the secretion rate and affinity of immunoglobuin $\mathrm{G}$ ( $\mathrm{IgG}$ ) from over 0.5 million individual cells enriched from spleen and bone marrow. ${ }^{[9]}$ As expected, the immunization resulted in dramatic increases in the heterogeneity of both single-cell secretion rates and affinities, which spanned at maximum 3 and $4 \operatorname{logs}$, respectively, and affinity maturation and its dynamics were nicely illustrated in the single-cell data, whereas parallel titer measurements only reflected affinity maturation by an increase of specific antibodies over time. A novel observation of this study was the fact that secretion rate and affinity do not correlate, a conclusion that could only be drawn due to the high-throughput single-cell resolved data. This correlation was a widespread assumption in the immunological community, but our experiments confirmed the independence of these two parameters. Furthermore, we observed that only a small fraction of all induced antibodies were antigenaffine (20-40\%). These non-specific antibodies are not detected in classical methods due to the absence of affinity for the target antigen. According to immunological consensus, the immune response should be rather targeted, and so the presence of almost $60-80 \%$ non-affine antibody-secreting cells is interesting. We have since used this data to model the immune response, ${ }^{[13]}$ and introduced a computational model that predicts the evolution of the distribution of affinities of antibody-secreting and memory cells during affinity maturation. These modelling experiments only represent the measured affinities when these non-affine cells are included, and we are very interested in describing their origin and potential functions. Since these antibodies were never detected before during target-specific serum titer assays, we internally call these cells and antibodies the 'dark matter of immunization', and their presence and function is of current research interest in my group.

\begin{tabular}{|c|c|c|c|c|c|c|c|c|}
\hline \multirow{2}{*}{\multicolumn{2}{|c|}{ Mouse }} & $\begin{array}{c}\text { Number of } \\
\text { analyzed cells }\end{array}$ & $\begin{array}{l}\text { Number of } \\
\text { IgG-SCs }\end{array}$ & $\begin{array}{c}\text { Number of } \\
\text { affine IgG-SCs }\end{array}$ & $\begin{array}{c}\text { Frequency of } \\
\text { IgG-SCs }\end{array}$ & $\begin{array}{l}\text { Frequency of } \\
\text { affine IgG-SCs }\end{array}$ & $\begin{array}{c}\text { Median } \\
\text { secretion rate }\end{array}$ & $\begin{array}{c}\text { Median } \\
\text { dissociation } \\
\text { constant }\end{array}$ \\
\hline & & $\mathrm{n}$ & \multirow{2}{*}{$\mathrm{n}$} & \multirow{2}{*}{$\frac{n}{87}$} & $\%$ & $\%$ & $\mathrm{lgG} / \mathrm{s}$ & $\mathrm{nM}$ \\
\hline & 1 & 20830 & & & 1.03 & 0.42 & 16.5 & 101.5 \\
\hline & 2 & 17115 & 237 & 65 & 1.38 & 0.38 & 17.4 & 67.0 \\
\hline & 3 & 43988 & 438 & 106 & 1.00 & 0.24 & 12.8 & 76.8 \\
\hline & \multicolumn{4}{|c|}{ Mean value } & 1.14 & 0.35 & 15.6 & 81.8 \\
\hline & & \multicolumn{3}{|c|}{ Standard deviation } & 0.17 & 0.07 & 1.8 & 13.2 \\
\hline
\end{tabular}
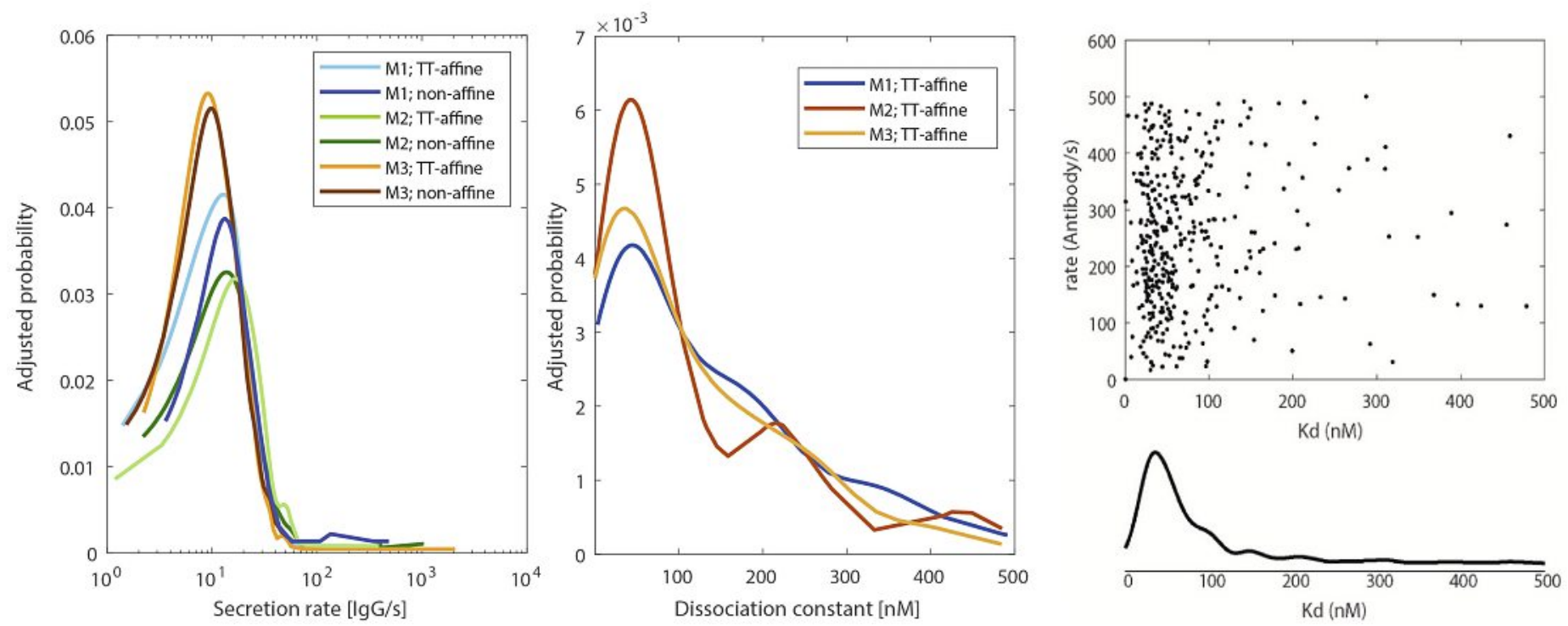

Fig. 4. Exemplary data extracted from three C57BL/6 Mice immunized with a commercial diphtheria-tetanus-poliomyelitis vaccine. The antibody repertoire was measured $24 \mathrm{~h}$ after challenge with tetanus toxoid, and the represented secreting-cells are activated memory cells. This method allows to quantitatively assay the generated memory that responds to challenge (see also refs [9]). The technology and employed data analysis allowed to quantitatively measure frequencies of antibody-secreting, affine and non-affine cells; as well as their median secretion rates and affinities. However, additionally we can use the data to compare various immunization protocols, and specifically compare the distributions of secretion rates (bottom, left), affinities (bottom, middle) and the correlation of affinity and secretion rate. Additional functionalities can be added (isotype, different antigens, etc.). Here, all three mice are immunized similarly, and the data is non-significantly different. These mice were part of a larger study ${ }^{[15]}$ where we measure the influence of vaccine additives on the quality and quantity of induced memory cells. See refs [15] for more explanation about the calculations. 
Although powerful and highly resolved, a thorough kinetic analysis using such an approach was time consuming, complex and carried a high animal load. Due to these limitations, our method seemed unsuitable to characterize or optimize different immunization schemes; a foreseen next step in the ERCSTG. However, within this original study, we also observed a quick spike in the frequency and affinity of immunoglobulin G-secreting cells (IgG-SCs) early after challenge with pure antigen. This spike was of interest since one of the major goals of vaccination is to prepare the body to rapidly secrete specific antibodies during a re-infection or challenge with the same antigen. We hypothesized that the recalled and reactivated IgG-SCs found in the spleen early after recall would be a good proxy to characterize the preceding immunization protocol and give an integrative overview of the success rate of the generation, evaluation and transfer of the immunization-induced IgG-repertoire. Indeed, as we have subsequently shown, ${ }^{[14]}$ early measurements extracted after challenge correlated strongly with preceding immunization protocols, and were free of newly generated antibody-secreting cells. We further confirmed that our phenotypic analysis of antibody-secreting cells after challenge strongly correlated with the different immunization schemes employed that is varying dose, antigen, formulation, or the duration of vaccination. A phenotypic comparison of IgG-SCs present in the spleen during immunization or after recall revealed similarities but also significant differences, showing again the dynamic nature of the immune response, but also illustrating differences in immediate response and memory. The developed approach introduced a novel, quantitative and functional highly resolved alternative to study the quality of the immunization-induced memory, and we now regularly use this method to quantify the quality of present memory (Fig. 4).

\subsection{Vaccination, Protection and Antibody Functionality}

Antibody-mediated protection after vaccination can be mediated by many different effector functions within the immune system, and so far we have mostly discussed antibody binding towards the antigen. Binding the antigen is only a first - although important - step for the various immunological effector functions sparked by antibodies. Possible antibody functionalities are manifold (Fig. 1A). Not all of these functions can be triggered by an antibody that simply recognizes the target with sufficient affinity. Some functions are strongly related to the isotype, or the presentation and density of the antigen on the expressing cell. The functional repertoire only overlaps partly with the present antigen-specific repertoire that is currently accessible through screening and sequencing. ${ }^{[15]}$ Additionally, it has been well-described that different biological agents need to induce diverse immune responses within an individual to be encountered successfully. In terms of antibodies, different threats need appropriate functional repertoires. This cannot only be true for the natural encountering of antigens but must also have an impact on the protection mediated by vaccines. When evaluating new vaccine candidates as well as existing vaccines, the variety of functional repertoires have to be carefully monitored and quantified to adapt the vaccine to generate the most beneficial and lasting response.

A current research focus is to introduce bioassays that allow studying various antibody-mediated functionalities (Fig. 1A). These projects built upon the already existing microfluidic technology, and by using specific bioassays that target various antibody functions and their biophysical parameters we aim to generate high-resolution data. The functional repertoires are followed over time to monitor repertoire evolution and memory, and the influence of introduced alterations in the vaccines are monitored on the level of the functional repertoires in a highly methodological fashion, allowing a quantitative approach to study the interactions between the vaccine components and the repertoires. We want to study the functional antibody repertoires after vaccinations with the goal to firstly quantify the various functional repertoires, secondly understand the interactions between vaccine components and the repertoires, and thirdly to influence the generation, evolution and storage of said repertoires. The deep and robust functional description of the repertoire and methodological alterations of the vaccine allow searching for bio-signatures within the data sets that generate an understanding of the interactions, a knowledge that can be used to steer the immune response towards wanted repertoires. Quantitative functional information is crucial to advance scientific knowledge in our applications, and the accurate analysis of immune responses to individual cell resolution are crucial.

\subsection{Novel Correlation of Functionalities}

Additionally we are also expanding our assays beyond protein secretion. Exemplarily, we correlate immune functionalities and metabolism on the single-cell level. Following activation of immune cells, metabolic pathways are switched on/off due to the engagement in energy-demanding processes such as secretion, division and differentiation. As of today, direct measurement of cellular metabolism is mostly carried out in bulk; neglecting cellular heterogeneity and sub-populations within the immune system. However, the function and activation is directly linked to each individual cell, and we need to assess cellular metabolism with single-cell resolution as well and in parallel to correlate metabolism to cellular function within the immune response.

\subsection{Sorting, Seuqnecing and Reverse Identification of Functional Cells}

Our methods enable to characterize the repertoire of individual functional cells at high-throughput, for instance to extract functional information from single IgG-SCs, and therefore single antibodies, such as specificities, affinities and the triggered immune functions that are of great interest for therapeutic candidates. Indeed, the natural antibody repertoire represents a prime library to find antibody leads for diagnostic, therapeutic or research applications. Whilst many technologies exist that enable the screening and mining of the antibody repertoire for antigen binding, the in-depth phenotypic characterization (affinity, specificity, relevant function) of the antibodies is done usually after selection and sequencing, and expression systems are needed. This laborious process represents a bottle-neck if many sequences need to be assayed. A much more directed approach includes the characterization of the antibodies in front of sequencing, and only to select antibodies with preferable biophysical properties. Therefore, we aim to put our thorough phenotypic characterization in front of total or targeted single-cell RNA sequencing with the possibility to select and sequence solely the events of interest. The workflow involves the analysis of the functionality of interest (phenotype), and through selection and sorting of the cells of interest allows studying the transcriptomic profile of the cell; ultimately linking the two. First, we want to apply this methodology towards the screening of the antibacterial antibody repertoire for functional active antibodies that allow bacterial killing through complement as a monoclonal species. These agents may offer new ways of fighting antibiotic resistance and bacterial infections with multiresistant bacteria; and the combination of the DropMap analysis with targeted sequencing allows to link phenotype (affinity, specificity, a secondary function such as phagocytosis, complement deposition) with the respective antibody sequence.

As a second application, the method is paired with a full single-cell transcriptomic analysis to functionally characterize the identity and survival of antibody-secreting cells along the immune response. The state-of-the-art efforts of immunologists to understand this complex system and its highly dynamic reactions and 
functionalities involved the categorization of immune cells into different cell subsets by their morphological phenotypes and molecular markers. These phenotypically and molecularly defined cell subsets were then assigned specific functions within the immune system - and in vitro and in vivo studies were used to verify these assignments. Here, we study the identity and characteristics of these cells reversely, starting with their function (antibody secretion) and moving towards the characterizations of the cell population(s). A special focus is laid on the antibody-secreting cells present during germinal center reactions within the spleen; and their identity and transcriptomic profiles are analyzed after sorting for functionality, i.e. antibody secretion. Here, we aim to find a better definition of the identity of antibody-secreting cells during the germinal center reaction, one that centers on their functionality.

\section{Outlook}

The deciphering of the dynamic processes at the single-cell level is critical to describe, understand and exploit the fundamental mechanisms underlying immunity, to develop new and improved strategies for vaccination and cancer immunotherapy, and to diagnose, improve and unravel novel strategies to combat inflammatory, autoimmune and infectious diseases. The usefulness of these methodologies is not only limited to vaccination, but were also applied to study and describe acute lymphocytic choriomeningitis virus (LCMV) infection in mice ${ }^{[16]}$ where we were able to describe significant differences in chronic and acute viral infections. In this article, we aimed to give an overview over the various research activities that are currently taking place in my lab, centered on antibody-mediated functionalities and vaccinations. However, we also aim to expand the application of our developed methodologies. We have already published the possibility to measure cytokines secreted from individual $\mathrm{T}$ and innate immune cells, ${ }^{[9]}$ and we are currently exploring different directions that study the usefulness of this quantitative, functional measure in personalized and precision medicine, diagnostics and immunooncology, and most recently SARS-CoV-2.

\section{Acknowledgements}

E.K. would like to acknowledge the proof-reading and correction of the text by O Bucheli, N. Aymerich, K. Portmann and I. Sigvaldadóttir. Furthermore, E.K. acknowledges generous funding from the 'The Branco Weiss Fellowship - Society in Science', ETH Zurich and received funding from the European Research Council (ERC) under the European Union's Horizon 2020 research and innovation program (Grant agreement No. 80336).

Received: June 15, 2020

[1] a) H. P. Roost, M. F. Bachmann, A. Haag, U. Kalinke, V. Pliska, H. Hengartner, R. M. Zinkernagel, Proc. Natl Acad. Sci. USA 1995, 92, 1257; b) D. Corti, J. Voss, S. J. Gamblin, G. Codoni, A. Macagno, D. Jarrossay, S. G. Vachieri, D. Pinna, A. Minola, F. Vanzetta, C. Silacci, B. M. Fernandez-Rodriguez, G. Agatic, S. Bianchi, I. Giacchetto-Sasselli, L. Calder, F. Sallusto, P. Collins, L. F. Haire, N. Temperton, J. P. M. Langedijk, J. J. Skehel, A. Lanzavecchia, Science 2011, 333, 850, DOI: 10.1126/science.1205669; c) J. J. Lavinder, Y. Wine, C. Giesecke, G. C. Ippolito, A. P. Horton, O. I. Lungu, K. H. Hoi, B. J. DeKosky, E. M. Murrin, M. M. Wirth, A. D. Ellington, T. Dorner, E. M. Marcotte, D. R. Boutz, G. Georgiou, Proc. Natl Acad. Sci. USA 2014, 111, 2259, DOI: 10.1073/pnas.1317793111; d) M. Knossow, M. Gaudier, A. Douglas, B. Barrere, T. Bizebard, C. Barbey, B. Gigant, J. J. Skehel, Virology 2002, 302, 294, DOI: 10.1006/viro.2002.1625; e) J. Foote, H. N. Eisen, Proc. Natl Acad. Sci. USA 1995, 92, 1254; f) A. W. Chung, M. P. Kumar, K. B. Arnold, W. H. Yu, M. K. Schoen, L. J. Dunphy, T. J. Suscovich, N. Frahm, C. Linde, A. E. Mahan, M. Hoffner, H. Streeck, M. E. Ackerman, M. J. McElrath, H. Schuitemaker, M. G. Pau, L. R. Baden, J. H. Kim, N. L. Michael, D. H. Barouch, D. A. Lauffenburger, G. Alter, Cell 2015, 163, 988, DOI: 10.1016/j.cell.2015.10.027.

[2] a) T. E. Michaelsen, J. Kolberg, A. Aase, T. K. Herstad, E. A. Hoiby, Scand. J. Immunol. 2004, 59, 34, DOI: 10.1111/j.0300-9475.2004.01362.x; b) P. M. Henson, Immunology 1967, 13, 261; c) A. DiGiandomenico, P.
Warrener, M. Hamilton, S. Guillard, P. Ravn, R. Minter, M. M. Camara, V. Venkatraman, R. S. Macgill, J. Lin, Q. Wang, A. E. Keller, J. C. Bonnell, M. Tomich, L. Jermutus, M. P. McCarthy, D. A. Melnick, J. A. Suzich, C. K. Stover, J. Exp. Med. 2012, 209, 1273, DOI: 10.1084/jem.20120033; d) A. DiGiandomenico, B. R. Sellman, Curr. Opin. Microbiol. 2015, 27, 78, DOI: 10.1016/j.mib.2015.07.014; e) Y. M. Lucisano Valim, P. J. Lachmann, Clin. Exp. Immunol. 1991, 84, 1, DOI: 10.1111/j.1365-2249.1991.tb08115.x.

[3] a) C. H. Lee, G. Romain, W. Yan, M. Watanabe, W. Charab, B. Todorova, J. Lee, K. Triplett, M. Donkor, O. I. Lungu, A. Lux, N. Marshall, M. A. Lindorfer, O. R. Goff, B. Balbino, T. H. Kang, H. Tanno, G. Delidakis, C. Alford, R. P. Taylor, F. Nimmerjahn, N. Varadarajan, P. Bruhns, Y. J. Zhang, G. Georgiou, Nat. Immunol. 2017, 18, 889, DOI: 10.1038/ni.3770; b) P. Bruhns, F. Jonsson, Immunol. Rev. 2015, 268, 25, DOI: 10.1111/imr.12350; c) K. Oishi, N. L. Koles, G. Guelde, M. Pollack, J. Infect. Dis. 1992, 165, 34 , DOI: 10.1093/infdis/165.1.34; d) B. W. Higgins, L. J. McHeyzer-Williams, M. G. McHeyzer-Williams, Trends Immunol. 2019, 40, 345, DOI: 10.1016/j. it.2019.01.012

[4] a) R. A. Manz, M. Lohning, G. Cassese, A. Thiel, A Radbruch, Int Immunol. 1998, 10, 1703, DOI: 10.1093/intimm/10.11.1703; b) M. A. Asensio, Y. W. Lim, N. Wayham, K. Stadtmiller, R. C. Edgar, J. Leong, R. Leong, R. A. Mizrahi, M. S. Adams, J. F. Simons, M. J. Spindler, D. S. Johnson, A. S. Adler, MAbs 2019, 11, 870, DOI: 10.1080/19420862.2019.1583995; c) H. I. Nakaya, T. Hagan, S. S. Duraisingham, E. K. Lee, M. Kwissa, N. Rouphael, D. Frasca, M. Gersten, A. K. Mehta, R. Gaujoux, G. M. Li, S. Gupta, R. Ahmed, M. J. Mulligan, S. Shen-Orr, B. B. Blomberg, S. Subramaniam, B. Pulendran, Immunity 2015, 43, 1186, DOI: 10.1016/j.immuni.2015.11.012.

[5] a) T. R. Poulsen, P. J. Meijer, A. Jensen, L. S. Nielsen, P. S. Andersen, J. Immunol. 2007, 179, 3841; b) H. N. Eisen, Cancer Immunol. Res. 2014, 2, 381, DOI: 10.1158/2326-6066.CIR-14-0029; c) A. Radbruch, G. Muehlinghaus, E. O. Luger, A. Inamine, K. G. C. Smith, T. Dörner, F. Hiepe, Nat. Rev. Immunol. 2006, 6, 741, DOI: 10.1038/nri1886; d) A. D. Gitlin, Z. Shulman, M. C. Nussenzweig, Nature 2014, 509, 637, DOI: 10.1038/ nature13300; e) Z. Shulman, A. D. Gitlin, J. S. Weinstein, B. Lainez, E. Esplugues, R. A. Flavell, J. E. Craft, M. C. Nussenzweig, Science 2014, 345 , 1058, DOI: 10.1126/science.1257861; f) A. D. Gitlin, L. von Boehmer, A. Gazumyan, Z. Shulman, T. Y. Oliveira, M. C. Nussenzweig, Immunity 2016 44, 769, DOI: 10.1016/j.immuni.2016.01.011; g) J. M. Tas, L. Mesin, G. Pasqual, S. Targ, J. T. Jacobsen, Y. M. Mano, C. S. Chen, J. C. Weill, C. A. Reynaud, E. P. Browne, M. Meyer-Hermann, G. D. Victora, Science 2016, 351, 1048, DOI: $10.1126 /$ science.aad3439.

[6] a) Y. Wine, A. P. Horton, G. C. Ippolito, G. Georgiou, Curr. Opin. Immunol. 2015, 35, 89, DOI: 10.1016/j.coi.2015.06.009; b) A. Szczawinska-Poplonyk, A. Breborowicz, H. Samara, L. Ossowska, G. Dworacki, Clin. Vaccine Immunol. 2015, 22, 875, DOI: 10.1128/CVI.00148-15; c) Y. Wine, D. R. Boutz, J. J. Lavinder, A. E. Miklos, R. A. Hughes, K. H. Hoi, S. T. Jung, A. P. Horton, E. M. Murrin, A. D. Ellington, E. M. Marcotte, G. Georgiou, Proc. Natl Acad. Sci. USA 2013, 110, 2993, DOI: 10.1073/pnas.1213737110.

[7] a) G. J. Nossal, Br. J. Exp. Pathol. 1958, 39, 544; b) G. J. Nossal, O. Makela, Аnпu. Rev. Microbiol. 1962, 16, 53, DOI: 10.1146/annurev. mi.16.100162.000413

[8] a) D. Lin, H. T. Maecker, Methods Mol. Biol. 2018, 1678, 37, DOI: 10.1007/978-1-4939-7346-0_3; b) A. H. C. Ng, S. Peng, A. M. Xu, W. J. Noh, K. Guo, M. T. Bethune, W. Chour, J. Choi, S. Yang, D. Baltimore, J. R. Heath, Lab Chip 2019, 19, 3011, DOI: 10.1039/c91c00538b; c) C. M. Mousset, W. Hobo, R. Woestenenk, F. Preijers, H. Dolstra, A. B. van der Waart, Cytometry A 2019, 95, 647, DOI: 10.1002/cyto.a.23724; d) G. Pastore, M. Carraro, E. Pettini, E. Nolfi, D. Medaglini, A. Ciabattini, Front Immunol. 2019, 10, 2304, DOI: 10.3389/fimmu.2019.02304.

[9] a) K. Eyer, R. C. L. Doineau, C. E. Castrillon, L. Briseno-Roa, V. Menrath, G. Mottet, P. England, A. Godina, E. Brient-Litzler, C. Nizak, A. Jensen, A. D. Griffiths, J. Bibette, P. Bruhns, J. Baudry, Nat. Biotechnol. 2017, 35, 977 , DOI: 10.1038/nbt.3964; b) Y. Bounab, K. Eyer, S. Dixneuf, M. Rybczynska, C. Chauvel, M. Mistretta, T. Tran, N. Aymerich, G. Chenon, J.F. Llitjos, F. Venet, G. Monneret, I Gillespie, P. Cortez, V. Moucadel, A. Pachot, A Troesch, P. Leissner, J. Textoris, J. Bibette, C. Guyard, J. Baudry, A. D. Griffiths, C. Védrine, Nat. Prot., in press.

[10] Y. N. Xia, G. M. Whitesides, Ann. Rev. Mat. Sci. 1998, 28, 153.

[11] a) N. T. D. Nhat, S. Todd, E. de Bruin, T. T. N. Thao, N. H. T. Vy, T. M. Quan, D. N. Vinh, J. van Beek, P. H. Anh, H. M. Lam, N. T. Hung, N. T. L. Thanh, H. L. A. Huy, V. T. H. Ha, S. Baker, G. E. Thwaites, N. T. N. Lien, T. T. K. Hong, J. Farrar, C. P. Simmons, N. V. V. Chau, M. Koopmans, M. F. Boni, Sci. Rep. 2017, 7, 6060, DOI: 10.1038/s41598-017-06177-0; b) C. T. D'Angio, C. P. Wyman, R. S. Misra, J. L. Halliley, H. Wang, J. E. Hunn, C. M. Fallone, F. E. Lee, Vaccine 2017, 35, 5163, DOI: 10.1016/j. vaccine.2017.07.115.

[12] B. Pulendran, R. Ahmed, Nat. Immunol. 2011, 12, 509;

[13] M. Molari, K. Eyer, J. Baudry, S. Cocco, R. Monasson, eLife 2020, 9 , e55678, DOI: 10.7554/eLife.55678.

[14] a) M. Rybczynska, J. Baudry, K. Eyer, Vaccine 2020, 38, 5337, DOI: 10.1016/j.vaccine.2020.05.006; b) K. Eyer, C. Castrillon, G. Chenon, J. Bibette, P. Bruhns, A. D. Griffiths, J. Baudry, J. Immunol. 2020, 4, DOI: 10.4049/jimmunol.2000112. 
[15] A. Gerard, A. Woolfe, G. Mottet, M. Reichen, C. Castrillon, V. Menrath, S. Ellouze, A. Poitou, R. Doineau, L. Briseno-Roa, P. Canales-Herrerias, P. Mary, G. Rose, C. Ortega, M. Delince, S. Essono, B. Jia, B. Iannascoli, O. Richard-Le Goff, R. Kumar, S. N. Stewart, Y. Pousse, B. Shen, K. Grosselin, B. Saudemont, A. Sautel-Caille, A. Godina, S. McNamara, K. Eyer, G. A. Millot, J. Baudry, P. England, C. Nizak, A. Jensen, A. D. Griffiths, P. Bruhns, C. Brenan, Nat. Biotechnol. 2020, DOI: 10.1038/s41587-020-0466-7.

[16] N. J. Krautler, A. Yermanos, A. Pedrioli, S. P. M. Welten, D. Lorge, U. Greczmiel, I. Bartsch, J. Scheuermann, J. D. Kiefer, K. Eyer, U. Menzel, V. Greiff, D. Neri, T. Stadler, S. T. Reddy, A. Oxenius, Cell Rep. 2020, 30, 997 , DOI: 10.1016/j.celrep.2019.12.088.

\section{License and Terms}

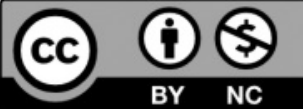

This is an Open Access article under the terms of the Creative Commons Attribution License CC BY_NC 4.0. The material may not be used for commercial purposes.

The license is subject to the CHIMIA terms and conditions: (http:// chimia.ch/component/sppagebuilder/?view=page \&id=12).

The definitive version of this article is the electronic one that can be found at https://doi.org/10.2533/chimia.2020.716 